\title{
Use of a Natural Sorbent as Alternative Solid-Phase Microextraction Coating for the Determination of Polycyclic Aromatic Hydrocarbons in Water Samples by Gas Chromatography-Mass Spectrometry
}

\author{
Natália G. Suterio, ${ }^{a}$ Sângela N. do Carmo, ${ }^{a}$ Dilma Budziak, ${ }^{b}$ Josias Merib ${ }^{c}$ and \\ Eduardo Carasek $*$,a \\ ${ }^{a}$ Departamento de Química, Universidade Federal de Santa Catarina, \\ 88040-900 Florianópolis-SC, Brazil \\ ${ }^{b}$ Departamento de Agronomia, Universidade Federal de Santa Catarina, \\ 89520-000 Curitibanos-SC, Brazil \\ 'Departamento de Farmacociências, Universidade Federal de Ciências da Saúde de Porto Alegre, \\ 90050-170 Porto Alegre-RS, Brazil
}

\begin{abstract}
In this study, the use of bracts as a natural sorbent in solid-phase microextraction was exploited for use in the determination of polycyclic aromatic hydrocarbons in water samples with separation/detection performed by gas chromatography-mass spectrometry. Fiber-to-fiber reproducibility was evaluated and the relative standard deviation (RSD) was lower than $14 \%$. Optimizations were performed using both the proposed and DVB/Car/PDMS (divinylbenzene/ carboxen/polydimethylsiloxane) fibers. The optimum extraction conditions were $80 \mathrm{~min}$ of extraction at $50{ }^{\circ} \mathrm{C}$ with $12 \%(\mathrm{~m} / \mathrm{v}) \mathrm{NaCl}$ for the bract fiber, and $100 \mathrm{~min}$ of extraction at $80{ }^{\circ} \mathrm{C}$ for the commercial fiber. The limits of detection and quantification for the proposed fiber were, respectively, 0.003 and $0.01 \mu \mathrm{g} \mathrm{L}^{-1}$ for fluorene, phenanthrene, anthracene and pyrene, and 0.03 and $0.1 \mu \mathrm{g} \mathrm{L}^{-1}$ for acenaphthylene, benzo $(a)$ anthracene and chrysene. The method using bract fiber provided relative recoveries ranging from 68 to $117 \%$, intraday and interday precisions lower than 17 and 19\%, respectively, and extraction efficiency similar to that of the DVB/Car/PDMS fiber.
\end{abstract}

Keywords: SPME, bract, biosorbent, PAHs, sample preparation

\section{Introduction}

Environmental problems caused by anthropogenic activities are continually increasing and gaining attention worldwide. One of the main concerns is the incomplete combustion of organic matter, which results in the release of a potentially toxic class of compounds called polycyclic aromatic hydrocarbons (PAHs). ${ }^{1}$ PAHs are a group of compounds which consist of two or more condensed aromatic rings composed of carbon and hydrogen atoms. ${ }^{2,3}$ Epidemiological and animal studies conducted by the International Agency for Research on Cancer (IARC) ${ }^{4}$ have shown that many PAHs have strong carcinogenic and mutagenic action. PAHs can enter the human body through dermal contact, inhalation and the ingestion of contaminated food or water. ${ }^{5}$

\footnotetext{
*e-mail: eduardo.carasek@ufsc.br
}

Therefore, the determination of PAHs in surface waters is very important since these are often used as drinking water supplies. ${ }^{6}$ For the determination of PAHs in different matrices, a sample preparation procedure is generally carried out. Sample preparation is a crucial step since it improves the selectivity and sensitivity of the analysis. In addition, the isolation of the analytes from potential interfering compounds present in the sample matrix and compatibility with the analytical instrumentation can be achieved by using an adequate sample preparation technique. ${ }^{7-9}$ The Environmental Protection Agency (EPA) of the United States of America has established liquidliquid extraction (LLE) and solid phase extraction (SPE) as sample preparation techniques to extract and concentrate PAHs in water samples. ${ }^{10,11}$ However, these procedures require large amounts of toxic organic solvents and involve a number of steps, which increases the possibility of errors. ${ }^{12}$ Recent trends have emphasized the importance 
of techniques which allow shorter analysis times, minimal reagent consumption and low residue generation. ${ }^{13,14}$

Solid-phase microextraction (SPME), proposed in the 1990s by Arthur and Pawliszyn, ${ }^{15}$ is a solventless technique with shorter extraction times compared to some classical approaches. It also allows easy coupling with chromatographic systems, reuse of the fiber and automation of the sample preparation step. ${ }^{1,16,17}$ SPME is based on the distribution of the analytes between the sample matrix and the extraction phase (fiber), combining sampling, isolation and enrichment in a single step. ${ }^{18,19}$ One important factor in relation to achieving high extraction efficiency in SPME is the fiber coating. ${ }^{17}$ In general, in their commercially available form, SPME fibers consist of a fused silica or metallic support coated with a polymeric material. ${ }^{7}$

Some disadvantages of SPME are associated with the fragility of fused silica and the high cost of the commercial fibers. To overcome these problems, alternative materials have been proposed for the support and also for the extraction phases in SPME. ${ }^{19-23}$ Very recently, our group ${ }^{24}$ introduced a bract fiber as a low-cost, renewable and natural sorbent material for SPME. This natural coating was supported on a nitinol (NiTi) alloy to ensure mechanical stability, high durability and corrosion resistance. ${ }^{25,26}$ The proposed SPME fiber exhibited excellent analytical performance compared to a commercial fiber when applied to the determination of organochlorine pesticides in water samples. ${ }^{24}$

The bract fiber represents a promising 'green' coating for solid-phase microextraction, since this biosorbent is natural, renewable and biodegradable, being obtained from Araucaria angustifolia (Bertoloni) Otto Kuntze, a coniferous tree present in southern Brazil. ${ }^{27}$ This heterogeneous material consists of $45 \%$ lignin and $46 \%$ holocellulose (cellulose and polyose), biopolymers with several polar and nonpolar chemical groups that can participate in several interactions with the analytes, including sorption, complexation and ion exchange. ${ }^{24,28}$ Moreover, the bract exhibits thermal stability at temperatures typically applied in gas chromatography analysis. ${ }^{24}$

The aim of this study was to increase the applicability of this promising biosorbent coating in solid-phase microextraction, through its use in an environmentallyfriendly technique for the determination of polycyclic aromatic hydrocarbons in water samples, with separation and quantification by gas chromatography-mass spectrometry (GC-MS). In addition, since the proposed method involves no organic solvent consumption and a natural sorbent (bract) is used, it is compatible with the principles of 'green chemistry', besides offering simplicity and low cost production.

\section{Experimental}

\section{Chemicals and solutions}

A standard solution at a concentration of $500 \mu \mathrm{g} \mathrm{mL}^{-1}$ of a PAH mix containing acenaphthylene, fluorene, phenanthrene, anthracene, pyrene, benzo $(a)$ anthracene and chrysene in acetone was obtained from Supelco (Bellefonte, PA, USA). A stock solution was prepared in methanol (Sigma-Aldrich, Saint Louis, USA) at a concentration of $50 \mu \mathrm{g} \mathrm{mL}{ }^{-1}$ for each analyte. Working solutions of the analytes were prepared by appropriate dilution of the stock solution in ultrapure water purified by a Mega Purity system (Billerica, USA). The analytical figures of merit were obtained by spiking lake water samples with the analytes at known concentrations. The lake water was filtrated prior to the analysis through PTFE (polytetrafluoroethylene) filters with a pore size of $0.45 \mu \mathrm{m}$ (Allcrom, São Paulo, Brazil). Sodium chloride (Vetec, Rio de Janeiro, Brazil) was used to evaluate the salting-out effect.

Instrumentation

In relation to the fiber-to-fiber reproducibility and method optimization, chromatographic analysis was performed using an Agilent 7820A gas chromatograph, with flame ionization detector (FID) equipped with a split/splitless injector and an Agilent DB-5 capillary column $(30 \mathrm{~m} \times 0.25 \mathrm{~mm} \times 0.25 \mu \mathrm{m}$; Santa Clara, CA, USA). To obtain the analytical parameters of merit, a comparison between the extraction efficiencies using the biosorbent-based fiber (bract) and a DVB/Car/PDMS (divinylbenzene/carboxen/polydimethylsiloxane) fiber and the application of the proposed analytical methodology were carried out using a Shimadzu GC-MS QP2010 Plus gas chromatograph, equipped with a split/splitless injector and mass spectrometer detector (Kyoto, Japan), with a Zebron ZB-5MS capillary column $(30 \mathrm{~m} \times 0.25 \mathrm{~mm} \times 0.25 \mu \mathrm{m}$; Torrance, CA, USA). The injection conditions and the column oven temperature program were the same for the GC-MS and GC-FID. The injection was performed in splitless mode, the injector temperature was set at $260{ }^{\circ} \mathrm{C}$ and the desorption time was $15 \mathrm{~min}$. The initial oven temperature was $80^{\circ} \mathrm{C}(1 \mathrm{~min})$, which was subsequently increased at $6{ }^{\circ} \mathrm{C} \mathrm{min}^{-1}$ to $300^{\circ} \mathrm{C}(10 \mathrm{~min})$. For the GC-MS, the transfer line and the ion source temperatures were set at 280 and $250^{\circ} \mathrm{C}$, respectively. Helium was used as the carrier gas at a flow rate of $1.0 \mathrm{~mL} \mathrm{~min}{ }^{-1}$. The mass spectrometer was operated in electron impact ionization (EI) mode at $70 \mathrm{eV}$. The PAHs were determined in selected ion monitoring (SIM) mode and the mass/charge $(\mathrm{m} / \mathrm{z}$ ) ratios 
employed are shown in Table 1 . The $m / z$ values in bold were used for the quantitative determination of the analytes.

Table 1. The $\mathrm{m} / \mathrm{z}$ values used for the determination of PAHs by GC-MS (values in bold were used for the quantification of the analytes)

\begin{tabular}{ll}
\hline Analyte & \multicolumn{1}{c}{$\mathrm{m} / \mathrm{z}$} \\
\hline Acenaphthylene & $\mathbf{1 5 2}, 153,151$ \\
Fluorene & $\mathbf{1 6 6}, 165,167$ \\
Phenanthrene & $\mathbf{1 7 8}, 176,179$ \\
Anthracene & $\mathbf{1 7 8}, 179,176$ \\
Pyrene & $\mathbf{2 0 2}, 203,200$ \\
Benzo $(a)$ anthracene & $\mathbf{2 2 8}, 226,229$ \\
Chrysene & $\mathbf{2 2 8}, 226,229$ \\
\hline
\end{tabular}

General materials

A knife mill, a granulometric sieve (200 mesh), nitinol wires ( $2 \mathrm{~cm}$ length and $0.128 \mathrm{~mm}$ diameter), epoxy glue (Brascola, São Bernardo do Campo, São Paulo, Brazil), and a heating block (Dist, Florianópolis, Santa Catarina, Brazil) were used for the preparation of the fiber. A thermostatic bath (Lab Companion RW 0525G, Seoul, South Korea), magnetic stirrers (Dist, Florianópolis, Santa Catarina, Brazil) and $40 \mathrm{~mL}$ vials (Supelco, Bellefonte, PA, USA) were used for the SPME extractions. A commercial fiber (DVB/Car/PDMS, 50/30 $\mu \mathrm{m}$; Supelco, Bellefonte, PA, USA) was used to compare the analyte extraction efficiencies.

\section{Preparation of the bract fibers}

The bracts used to produce the SPME fibers were obtained from trees cultivated in the city of Curitibanos (Santa Catarina, Brazil). The material was triturated in a knife mill and the required particle size $(<200$ mesh) was obtained by passing the material through a sieve. The bract fiber was prepared according to a method developed in our previous study. ${ }^{24}$ The bract powder ( $<200$ mesh) was immobilized, using epoxy glue, on a nitinol wire with $2 \mathrm{~cm}$ length and $0.128 \mathrm{~mm}$ thickness. In the next step, the nitinol covered with biosorbent was inserted in the heating block at $180{ }^{\circ} \mathrm{C}$ for $90 \mathrm{~min}$. The fiber was then conditioned at $260{ }^{\circ} \mathrm{C}$ for $60 \mathrm{~min}$ in a $\mathrm{GC}$ injection port.

The characterization of the bract fiber performed in previous study showed that bract is comprised of total extractives (6\%), lignin (45\%) and holocellulose (cellulose and polyoses) (46\%). The thermogravimetric analysis revealed that this biosorbent started to undergo thermal decomposition around $300{ }^{\circ} \mathrm{C}$, and the scanning electron microscopy (SEM) demonstrated that the bract fiber exhibited a highly porous and rough surface. In addition, the film thickness was evaluated by SEM of the cross-section of the fiber, and a thickness of approximately $60 \mu \mathrm{m}$ was observed. The evaluation of the durability of biosorbentbased fiber was also carried out in previous study by comparing the responses using a fiber subjected to a number of extraction/desorption cycles. This result showed that the proposed fiber allowed at least 50 extraction cycles with no significant loss of extraction efficiency. ${ }^{24}$

\section{Fiber-to-fiber reproducibility}

The fiber-to-fiber reproducibility was assessed based on the relative standard deviation (RSD) obtained using three biosorbent-based fibers in the extraction of PAHs in ultrapure water samples spiked at concentrations of $150 \mu \mathrm{g} \mathrm{L}^{-1}$ of each analyte. In this procedure, the fibers were immersed in the sample for $45 \mathrm{~min}$ at $60{ }^{\circ} \mathrm{C}$. The chromatographic analysis was performed using GC-FID.

\section{Optimization of SPME procedure}

A multivariate approach was adopted to optimize the extraction conditions for the proposed analytical methodology using bract and commercial fibers. A central composite design, totalizing 17 experiments, including a triplicate at the central point was used. The optimization strategies using both bract and commercial fibers were the same and the variables studied were extraction temperature $\left(20-80^{\circ} \mathrm{C}\right)$, extraction time (30-120 min) and sodium chloride concentration $(0-20 \% \mathrm{~m} / \mathrm{v})$. The SPME was carried out in direct-immersion mode (DI-SPME). In this case, $25 \mathrm{~mL}$ of the water samples spiked with

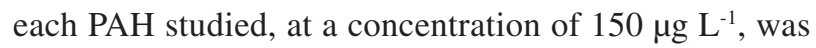
transferred to a $40 \mathrm{~mL}$ vial and kept under constant magnetic stirring at $1000 \mathrm{rpm}$. After the extractions, the fiber was immediately inserted into the GC injection port for the thermal desorption of the analytes at $260{ }^{\circ} \mathrm{C}$ for $15 \mathrm{~min}$. The analysis was carried out by GC-FID in splitless mode.

\section{Comparison of the extraction efficiencies using bract and DVB/Car/PDMS fibers}

After optimizing the analytical procedure, the efficiency of the bract fiber was compared with that of a commercial fiber (DVB/Car/PDMS) for the extraction/determination of the PAHs studied. An aliquot $(25 \mathrm{~mL})$ of the ultrapure water spiked with the analytes at a concentration of $4 \mu \mathrm{g} \mathrm{L}^{-1}$ was transferred to a $40 \mathrm{~mL}$ vial with $12 \%(\mathrm{~m} / \mathrm{v})$ of $\mathrm{NaCl}$ at $50{ }^{\circ} \mathrm{C}$ for $80 \mathrm{~min}$, when bract fiber was employed. For the extractions carried out using the commercial fiber, the 
conditions employed were $80^{\circ} \mathrm{C}$ for $100 \mathrm{~min}$ without $\mathrm{NaCl}$. The chromatographic analysis was performed by GC-MS.

Analytical parameters of merit and application of the proposed method

Calibration curves were constructed using fresh water samples obtained from a lake (Lagoa do Peri, Florianópolis, Santa Catarina, Brazil) spiked with the analytes to determine the linear range, correlation coefficients (r), limits of quantification (LOQ) and limits of detection (LOD) using the proposed fiber. The LOQ was defined as the first concentration of the calibration curve and the LOD as a third of the LOQ value.

The precision and accuracy of the method with the proposed fiber were determined by performing extractions using the lake water samples (Lagoa do Peri) containing different concentrations of the analytes $(0.01$, 1.0 and $4.0 \mu \mathrm{g} \mathrm{L}^{-1}$ for all analytes except in the case of acenaphthylene, for which $0.1,1.0$ and $4.0 \mu \mathrm{g} \mathrm{L}^{-1}$ were used). The accuracy was assessed based on the relative recoveries obtained for the analytes, under the optimized extraction conditions. Intraday precision was determined through three extractions on the same day $(\mathrm{n}=3)$ and interday precision through three extractions per day performed on three separated days $(n=9)$.

The applicability of the proposed method using the bract fiber was evaluated by performing extractions using four samples collected from different areas of a lake (Lagoa do Peri) that is one of the most important potable water sources supplying the city of Florianópolis. The geographical locations of the four sampling points are shown in Figure 1. In these experiments, the analysis was carried out by GC-MS.
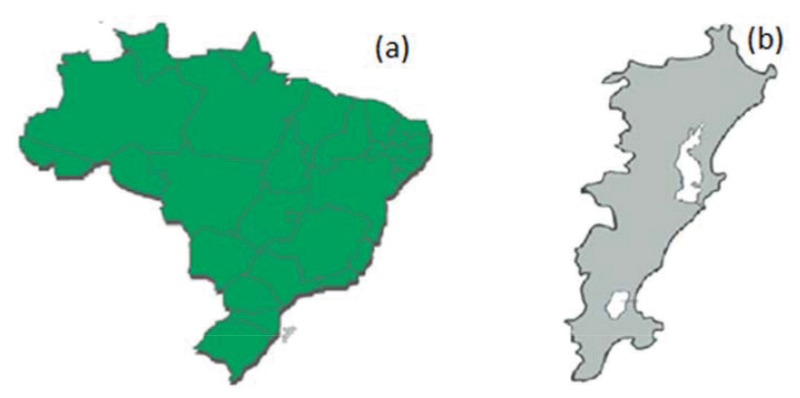

(c)

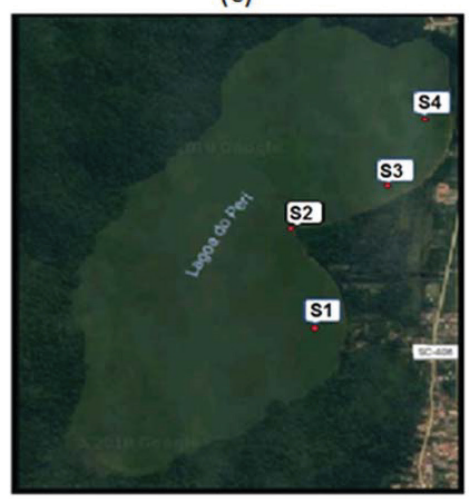

Figure 1. (a) Brazil; (b) island of Santa Catarina, Florianópolis; (c) Lagoa do Peri, with geographical locations of sampling points: (S1) -27738344, -48516683 ; (S2) -27.731511, -48.519265; (S3) -27.728242, -48.511405; (S4) $-27.726150,-48.509530$.

\section{Results and Discussion}

Fiber-to-fiber reproducibility

The reproducibility of the fiber production process was verified using three different fibers produced according to the same methodology. A bar graph of the normalized chromatographic peak areas obtained for each analyte is shown in Figure 2.

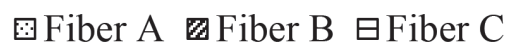

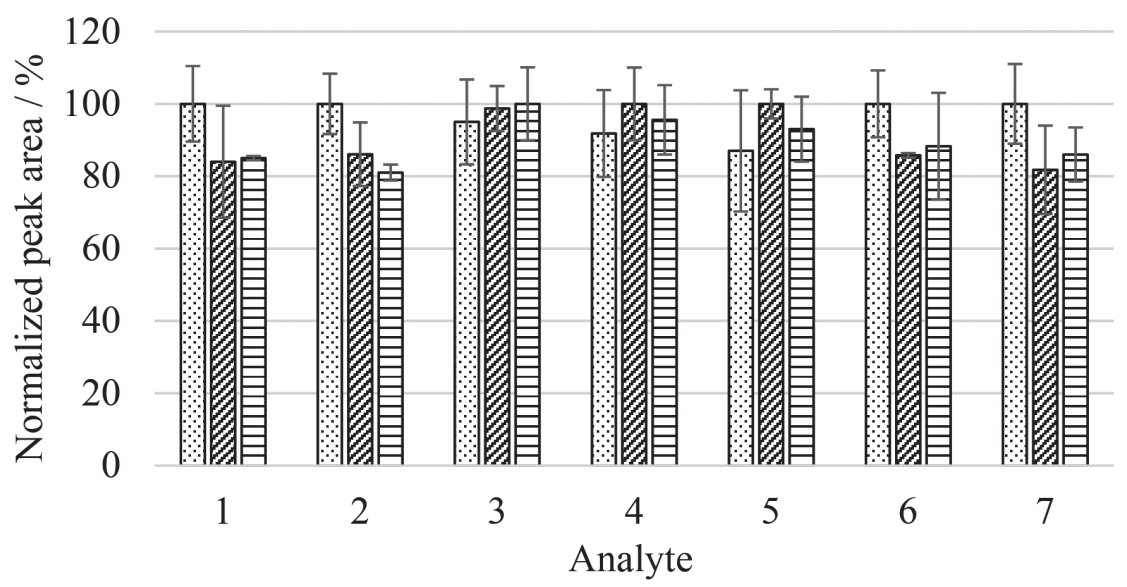

Figure 2. Chromatographic responses obtained after DI-SPME extractions with biosorbent-based fibers A, B and C with separation/detection by GC-FID. Analytes: (1) acenaphthylene; (2) fluorene; (3) phenanthrene; (4) anthracene; (5) pyrene; (6) benzo(a)anthracene and (7) chrysene. 
It can be observed that different biosorbent-based fibers prepared according to the same procedure provided similar results for the extraction of the compounds studied. The values for the relative standard deviation obtained from three samples of the proposed fibers were lower than $14 \%$.

\section{Optimization of the SPME procedure}

The SPME parameters that can influence the extraction of the PAHs were optimized using both the bract fiber and the commercial fiber (DVB/Car/PDMS). The geometric means of the chromatographic peak areas corresponding to the analytes were used as the response for the experimental planning. The data obtained from the chromatograms were evaluated using the software Statistica 8.0. ${ }^{29}$ The response surfaces obtained for the biosorbent-based fiber and DVB/Car/PDMS are shown in Figures 3 ( $a$ and $b$ ) and 4 (a and b), respectively.

According to Figure 3, the conditions of $80 \mathrm{~min}$ of extraction at $50{ }^{\circ} \mathrm{C}$ provided the highest extraction

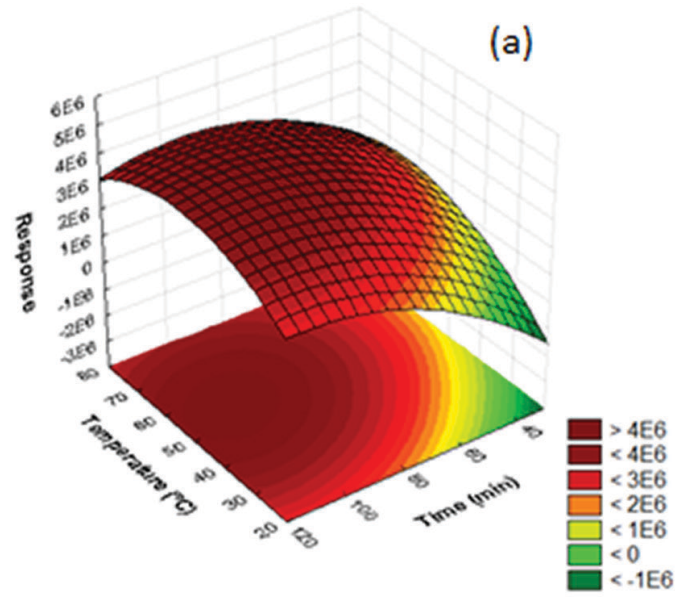

efficiency. In addition, satisfactory responses were obtained with $12 \%(\mathrm{~m} / \mathrm{v})$ of $\mathrm{NaCl}$ added to the sample and, therefore, these conditions were chosen for further experiments. For the commercial fiber, the best results were obtained using 100 min of extraction time at $80{ }^{\circ} \mathrm{C}$ without $\mathrm{NaCl}$, as represented in Figure 4.

The film thickness of the extraction phase influences the time required to reach the equilibrium condition in SPME analysis. In general, fibers with greater film thickness will take longer to reach equilibrium. Considering that the thickness of the DVB/Car/PDMS coating is $80 \mu \mathrm{m}$ while that of the proposed fiber is approximately $60 \mu \mathrm{m},{ }^{24}$ a shorter extraction time was observed for the proposed natural fiber.

\section{Comparison of extraction efficiencies}

The extraction efficiencies were compared using the proposed fiber and a commercial fiber (DVB/Car/PDMS), applying the previously optimized conditions. A bar graph

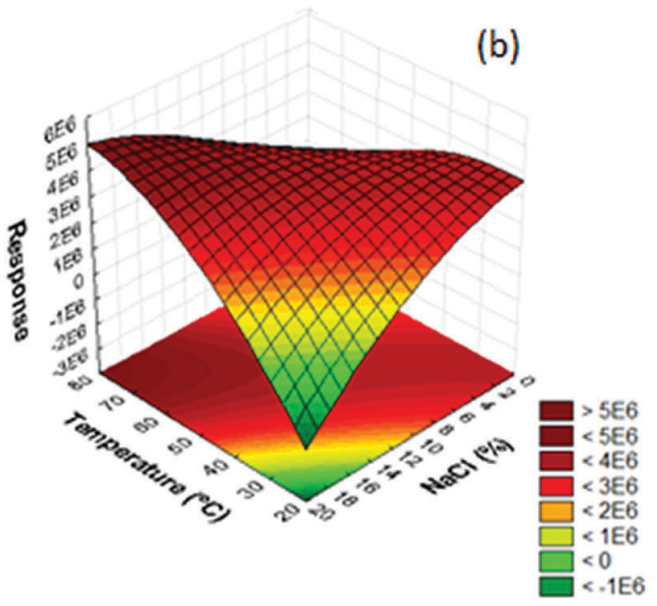

Figure 3. Response surfaces obtained for the extraction of PAHs by DI-SPME using the biosorbent-based fiber: (a) temperature versus extraction time; (b) temperature versus $\mathrm{NaCl}$ concentration.
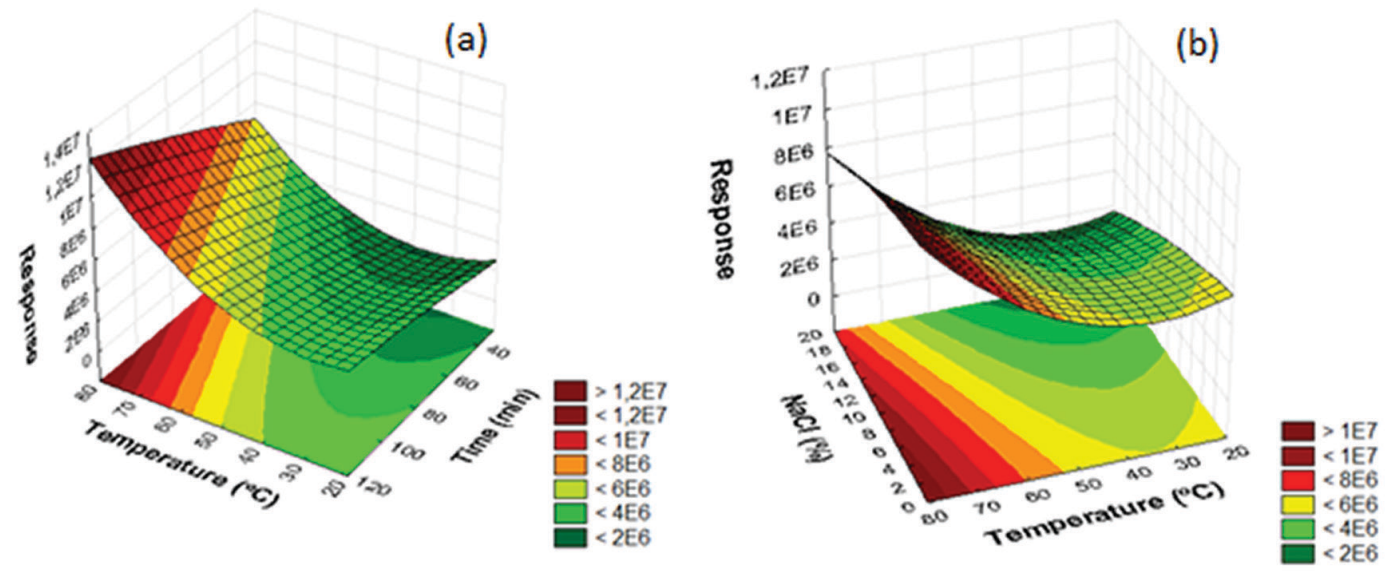

Figure 4. Response surfaces obtained for the extraction of PAHs by DI-SPME using DVB/Car/PDMS fiber: (a) temperature versus extraction time; (b) temperature versus $\mathrm{NaCl}$ concentration. 
of the normalized peak area taking into account the film thickness of each fiber is shown in Figure 5.

It can be observed in Figure 5 that the extraction performance of the DVB/Car/PDMS coating for acenaphthylene, fluorene, phenanthrene, anthracene and benzo $(a)$ anthracene was higher compared with the bract fiber, while for pyrene and chrysene the proposed fiber presented a higher efficiency. However, extraction efficiencies of approximately $80 \%$ of those obtained with the DVB/Car/PDMS coating were achieved for fluorene, phenanthrene and benzo( $a$ )anthracene using the proposed fiber, while for anthracene the efficiency achieved was around $90 \%$. Therefore, the proposed fiber presented very satisfactory extraction performance for the PAHs when compared to the commercial fiber, with the exception of acenaphthylene.

These results verify the high potential for the use of the bract fiber as a sorbent phase for SPME. Moreover, bract is natural, renewable and biodegradable, and its chemical composition provides numerous possibilities of chemical interaction for a wide range of compounds. In addition, the proposed fiber has a lifetime of around 50 extraction/ desorption cycles and offers satisfactory thermal and mechanical stability. The coating technique used for the fiber preparation is easy, fast, reproducible and it represents a low-cost alternative when compared to commercial extraction phases for SPME (which are approximately 200 times more expensive). ${ }^{24}$

Bract contains compounds such as lignin and holocellulose (cellulose and polyose) ${ }^{24}$ Lignin biopolymers contain a number of aromatic moieties and, therefore, $\pi-\pi$ interactions allow the efficient extraction of PAHs. In addition, the bract fiber exhibits a highly porous and rough surface, which can facilitate the physical process involved in the sorption of the analytes. ${ }^{24}$

\section{Analytical parameters of merit}

Analytical parameters of merit (linear range, r, LOD and LOQ) were determined to evaluate the method developed and the results obtained are shown in Table 2. The linear regression coefficients (r) of the calibration curves varied from 0.9773 for chrysene to 0.9988 for acenaphthylene, which indicates good linear correlations. The LOQ

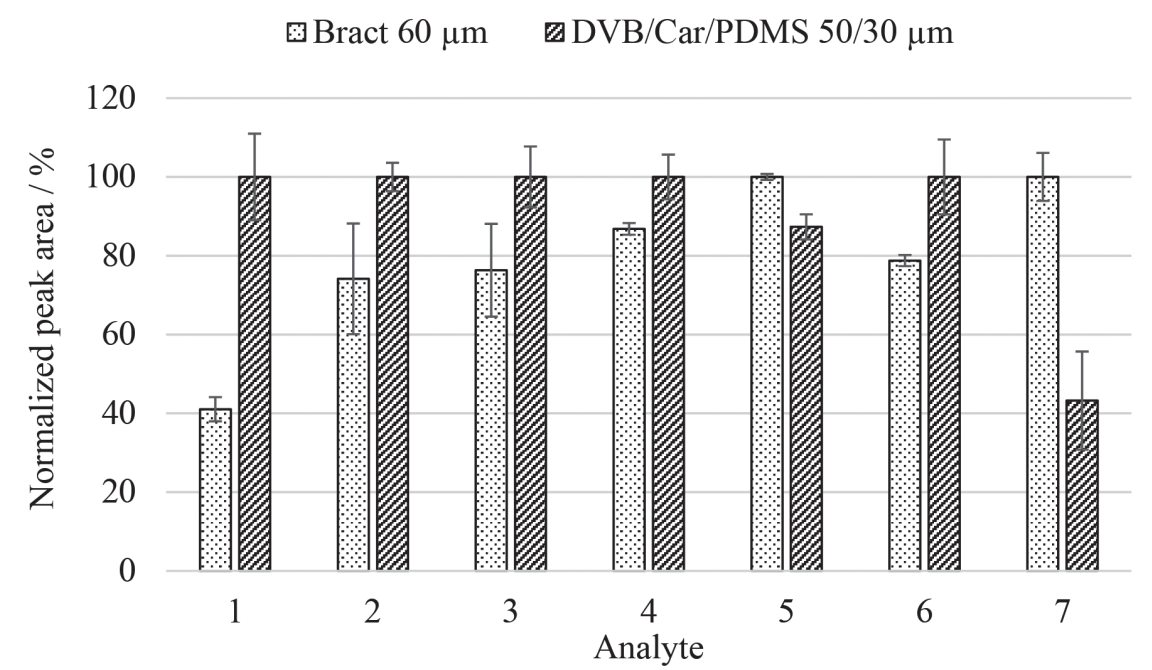

Figure 5. Comparison of extraction efficiencies of the biosorbent-based and DVB/Car/PDMS coatings for determination of PAHs. Analytes: (1) acenaphthylene; (2) fluorene; (3) phenanthrene; (4) anthracene; (5) pyrene; (6) benzo(a)anthracene and (7) chrysene.

Table 2. Linear range, linear equation, correlation coefficient (r) and limits of detection (LOD) and quantification (LOQ) obtained for the extraction of PAHs by DI-SPME using the biosorbent-based fiber

\begin{tabular}{|c|c|c|c|c|c|}
\hline Analyte & Linear range / $\left(\mu \mathrm{g} \mathrm{L}^{-1}\right)$ & Linear equation & $\mathrm{r}$ & $\mathrm{LOD}^{\mathrm{a}} /\left(\mu \mathrm{g} \mathrm{L}^{-1}\right)$ & $\mathrm{LOQ}^{\mathrm{a}} /\left(\mu \mathrm{g} \mathrm{L}^{-1}\right)$ \\
\hline Acenaphthylene & $0.10-4.00$ & $y=441291 x+22642$ & 0.9988 & 0.03 & 0.10 \\
\hline Fluorene & $0.01-4.00$ & $y=668414 x+22697$ & 0.9963 & 0.003 & 0.01 \\
\hline Phenanthrene & $0.01-4.00$ & $y=\left(1.5 \times 10^{6}\right) x+62369$ & 0.9927 & 0.003 & 0.01 \\
\hline Anthracene & $0.01-4.00$ & $y=\left(1.6 \times 10^{6}\right) x+68824$ & 0.9938 & 0.003 & 0.01 \\
\hline Pyrene & $0.01-4.00$ & $y=\left(2.3 \times 10^{6}\right) x+23480$ & 0.9981 & 0.003 & 0.01 \\
\hline $\operatorname{Benzo}(a)$ anthracene & $0.1-4.00$ & $y=\left(1.7 \times 10^{6}\right) x-49650$ & 0.9998 & 0.03 & 0.1 \\
\hline Chrysene & $0.1-4.00$ & $y=\left(1.7 \times 10^{6}\right) x-40286$ & 0.9773 & 0.03 & 0.1 \\
\hline
\end{tabular}

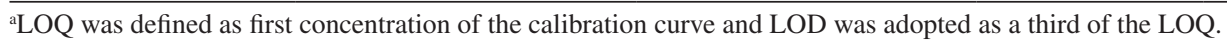


and LOD were, respectively, 0.01 and $0.003 \mu \mathrm{g} \mathrm{L} \mathrm{L}^{-1}$ for fluorene, phenanthrene, anthracene and pyrene and 0.1 and $0.03 \mu \mathrm{g} \mathrm{L}{ }^{-1}$ for acenaphthylene, benzo $(a)$ anthracene and chrysene. The European Union directive 2013/39/EU ${ }^{30}$ establishes a maximum limit of $0.1 \mu \mathrm{g} \mathrm{L}{ }^{-1}$ for anthracene in surface waters. Therefore, the method proposed using the biosorbent-based fiber exhibited an LOQ value 10 times lower than this maximum limit concentration.

A comparison of the results obtained in this study with data previously reported in the literature for the determination of PAHs can be seen in Table 3. The proposed method using bract fiber, when compared with studies previously reported in the literature employing SPME and cold fiber SPME (CF-SPME), provides lower limits of detection and quantification, except for acenaphthylene, benzo $(a)$ anthracene and chrysene determination using CF-SPME. ${ }^{1,31}$ In a study using SPE, the LOD and LOQ values were also higher when compared with those of the proposed method..$^{32}$ The low LOD and LOQ obtained using the bract fiber is possibly due to the strong $\pi-\pi$ interactions occurring among the aromatic moieties of the sorbent phase with the PAHs determined in this study.

The precision (RSD) and accuracy of the method using bract fiber was evaluated by spiking lake water samples at different concentrations. The accuracy of the method was assessed through the relative recovery of analytes $(\mathrm{n}=3)$. Intraday precision was verified through three extractions on the same day $(\mathrm{n}=3)$ and interday precision was evaluated through three extractions per day on three separated days $(n=9)$. As shown in Table 4 , the relative recoveries ranged from $68 \%$ for acenaphthylene to $117 \%$ for benzo $(a)$ anthracene, the intraday precision ranged from $0.7 \%$ for fluorene to $17 \%$ for benzo $(a)$ anthracene, and the interday precision varied from $0.3 \%$ for pyrene to $19 \%$ for acenaphthylene.

\section{Application of the proposed method}

The analytical method proposed in this study was applied to four different samples collected in different areas of Lagoa do Peri in Florianópolis. In this evaluation, none of the samples showed peaks related to the analytes studied; however, the analytes could be present in concentrations below the limits of detection. Figure 6 shows two chromatograms obtained using spiked (line a) and non-spiked (line b) fresh water samples (collected from a lake) with extraction using the biosorbent-based fiber in DI-SPME and analysis by GC-MS.

\section{Conclusions}

In this study, an analytical methodology using a biosorbent-based (bract) coating for SPME was successfully developed to determine PAHs in water samples. The natural sorbent exhibited very satisfactory analytical performance with excellent extraction efficiency for the analytes. In addition, the proposed fiber exhibited some important features including very low cost and simplicity of production, as well as valuable environmental aspects related to the natural sorbent (renewable and biodegradable) used in this approach. Taking into account these promising characteristics, further studies involving the applicability

Table 3. Comparison of the proposed method using biosorbent-based fiber with studies previously reported in the literature for the determination of PAHs

\begin{tabular}{|c|c|c|c|c|}
\hline Reference & Extraction technique & Sample matrix & $\mathrm{LOD} /\left(\mu \mathrm{g} \mathrm{L}^{-1}\right)$ & $\mathrm{LOQ} /\left(\mu \mathrm{g} \mathrm{L}^{-1}\right)$ \\
\hline This study & $\begin{array}{l}\text { SPME with bract fiber } \\
\qquad(60 \mu \mathrm{m})\end{array}$ & lake water & $\begin{array}{c}0.03^{\mathrm{a}, \mathrm{f}, \mathrm{g}} \\
0.003^{\mathrm{b}, \mathrm{d}, \mathrm{de}}\end{array}$ & $\begin{array}{c}0.10^{\mathrm{a}, \mathrm{f}, \mathrm{g}} \\
0.01^{\mathrm{b}, \mathrm{c}, \mathrm{d}, \mathrm{e}}\end{array}$ \\
\hline 1 & $\begin{array}{l}\text { SPME with PDMS fiber } \\
\qquad(30 \mu \mathrm{m})\end{array}$ & tap water & $\begin{array}{c}0.06^{\mathrm{a}} \\
0.11^{\mathrm{b}, \mathrm{c}, \mathrm{d}} \\
0.19^{\mathrm{e}} \\
0.60^{\mathrm{f}} \\
0.44^{\mathrm{g}}\end{array}$ & $\begin{array}{c}0.21^{\mathrm{a}} \\
0.38^{\mathrm{b}, \mathrm{c}, \mathrm{d}} \\
0.63^{\mathrm{e}} \\
1.67^{\mathrm{f}} \\
1.48^{\mathrm{g}}\end{array}$ \\
\hline 31 & $\begin{array}{l}\text { CF-SPME with PDMS fiber } \\
\qquad(100 \mu \mathrm{m})\end{array}$ & spring water & $\begin{array}{c}0.0015^{\mathrm{a}} \\
0.02^{\mathrm{b}} \\
0.046^{\mathrm{c}} \\
0.033^{\mathrm{d}} \\
0.016^{\mathrm{e}} \\
0.015^{\mathrm{f}} \\
0.028^{\mathrm{g}}\end{array}$ & $\begin{array}{c}0.05^{\mathrm{a}} \\
0.06^{\mathrm{b}} \\
0.15^{\mathrm{c}} \\
0.10^{\mathrm{d}} \\
0.054^{\mathrm{e}} \\
0.05^{\mathrm{f}} \\
0.094^{\mathrm{g}}\end{array}$ \\
\hline 32 & SPE with $300 \mathrm{mg}$ of $\mathrm{C} 18$ & water samples & $\begin{array}{c}10.0^{\mathrm{a}, \mathrm{e}} \\
1.0^{\mathrm{b}} \\
5.0^{\mathrm{g}}\end{array}$ & $\begin{array}{c}33.3^{\mathrm{a}, \mathrm{e}} \\
3.3^{\mathrm{b}} \\
16.6^{\mathrm{g}}\end{array}$ \\
\hline
\end{tabular}

${ }^{\mathrm{a}}$ Acenaphthylene; ${ }^{\mathrm{b}}$ fluorene; ${ }^{\mathrm{c}}$ phenanthrene; ${ }^{\mathrm{d} a n t h r a c e n e ; ~}{ }^{\mathrm{e}}$ pyrene; ${ }^{\mathrm{f}} \mathrm{benzo}(a)$ anthracene; ${ }^{\mathrm{g}}$ chrysene. LOD: limit of detection; LOQ: limit of quantification; SPME: solid phase microextraction; PDMS: polydimethylsiloxane; CF-SPME: cold fiber-SPME; SPE: solid phase extraction. 
Table 4. Relative recoveries and precision (interday and intraday) for the determination of PAHs in lake water samples

\begin{tabular}{|c|c|c|c|c|c|}
\hline Analyte & & $\begin{array}{l}\text { Spiked concentration / } \\
\qquad\left(\mu \mathrm{g} \mathrm{L}^{-1}\right)\end{array}$ & $\begin{array}{l}\text { Relative recovery } \\
\qquad(\mathrm{n}=3) / \%\end{array}$ & $\begin{array}{c}\text { Intraday precision } \\
(\mathrm{n}=3) / \%\end{array}$ & $\begin{array}{c}\text { Interday precision } \\
(\mathrm{n}=9) / \%\end{array}$ \\
\hline & & 0.10 & 68 & 5 & 13 \\
\hline \multirow[t]{2}{*}{ Acenaphthylene } & & 1.00 & 70 & 0.9 & 4 \\
\hline & & 4.00 & 72 & 10 & 19 \\
\hline \multirow{3}{*}{ Fluorene } & & 0.01 & 81 & 2 & 18 \\
\hline & & 1.00 & 89 & 0.6 & 4 \\
\hline & & 4.00 & 80. & 0.7 & 18 \\
\hline \multirow{3}{*}{ Phenanthrene } & & 0.01 & 85 & 7 & 11 \\
\hline & & 1.00 & 100 & 3 & 0.3 \\
\hline & & 4.00 & 91 & 2 & 13 \\
\hline \multirow{3}{*}{ Anthracene } & & 0.01 & 87 & 10 & 9 \\
\hline & & 1.00 & 99 & 3 & 3 \\
\hline & & 4.00 & 96 & 2 & 17 \\
\hline \multirow{3}{*}{ Pyrene } & & 0.01 & 98 & 9 & 6 \\
\hline & & 1.00 & 110 & 6 & 0.7 \\
\hline & & 4.00 & 99 & 4 & 14 \\
\hline \multirow{3}{*}{$\operatorname{Benzo}(a)$ anthracene } & & 0.1 & 105 & 9 & 11 \\
\hline & & 1.00 & 117 & 4 & 8 \\
\hline & & 4.00 & 96 & 15 & 16 \\
\hline \multirow{3}{*}{ Chrysene } & & 0.1 & 90 & 17 & 13 \\
\hline & & 1.00 & 87 & 1 & 7 \\
\hline & & 4.00 & 99 & 15 & 16 \\
\hline 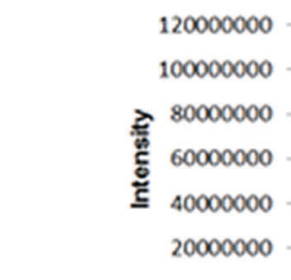 & $\begin{array}{l}1 \\
-\end{array}$ & 2 & $3^{4}$ & 5 & $\begin{array}{l}-(a) \\
-(b)\end{array}$ \\
\hline 0 & & 17 & $\begin{array}{c}21 \\
\text { Time }(\mathrm{mi}\end{array}$ & 25 & 29 \\
\hline
\end{tabular}

Figure 6. Chromatograms (GC-MS) obtained from a lake water sample spiked at $4 \mu \mathrm{g} \mathrm{L}{ }^{-1}$ (a) and non-spiked lake water sample (b). Elution order: (1) acenaphthylene; (2) fluorene; (3) phenanthrene; (4) anthracene; (5) pyrene; (6) benzo(a)anthracene and (7) chrysene.

of this 'green' sorbent coupled with other microextraction techniques should be conducted.

\section{Acknowledgments}

The authors are grateful to CNPq (Conselho Nacional de Desenvolvimento Científico e Tecnológico) and CAPES (Coordenação de Aperfeiçoamento de Pessoal de Nível Superior) for the financial support which made this research possible.

\section{References}

1. Coelho, E.; Ferreira C.; Almeida, C. M. M.; J. Braz. Chem. Soc. 2008, 19, 1084.
2. Menzie, C. A.; Potocki, B. B.; Santodonato, J.; Environ. Sci. Technol. 1992, 26, 1278.

3. Zhang, K.; Zhang, B.-Z.; Li, S.-M.; Wong, C. S.; Zeng, E. Y.; Sci. Total Environ. 2012, 431, 245.

4. International Agency for Research on Cancer (IARC); Evaluation of the Carcinogenic Risk of Chemicals to Humans: Polynuclear Aromatic Compounds, Chemical, Environmental and Experimental Data, vol. 32; IARC: Lyon, France, 1983.

5. Pereira Netto, A. D.; Moreira, J. C.; Dias, A. E. X. O.; Arbilla, G.; Ferreira, L. F. V.; Oliveira, A. S.; Barek, J.; Quim. Nova 2000, 23, 765 .

6. Brum, D. M.; Netto, A. D. P.; J. Hazard. Mater. 2009, 165, 447.

7. Ahmadi, M.; Elmongy, H.; Madrakian, T.; Abdel-Rehim, M.; Anal. Chim. Acta 2017, 958, 1. 
8. Luque de Castro, M. D.; Delgado-Povedano, M. M.; Anal. Chim. Acta 2014, 806, 74.

9. Raynie, D. E.; Anal. Chem. 2006, 78, 3997.

10. Clavijo, S.; Fernandez, M.; Forteza, R.; Brunetto, M. R.; Cerda, V.; Anal. Methods 2014, 6, 3335.

11. Hosseini, M. H.; Rezaee, M.; Akbarian, S.; Mizani, F.; Pourjavid, M. R.; Arabieh, M.; Anal. Chim. Acta 2013, 762, 54.

12. Clement, R. E.; Yang, P. W.; Koester, C. J.; Anal. Chem. 2001, 73,2761

13. Cassiano, N. M.; Barreiro, J. C.; Cass, Q. B.; J. Braz. Chem. Soc. 2014, 25, 9.

14. Oliveira, E.; J. Braz. Chem. Soc. 2003, 14, 174.

15. Arthur, C. L.; Pawliszyn, J.; Anal. Chem. 1990, 62, 2145.

16. Coelho, A. R. A.; Oliveira, I. M. F.; Cardeal, Z. L; J. Braz. Chem. Soc. 2009, 20, 530.

17. Kaykhaii, M.; Dicinoski, G. W.; Smedley, R.; Pawliszyn, J.; Haddad, P. R.; J. Chromatogr. A 2010, 1217, 3452.

18. Lord, H.; Pawliszyn, J.; J. Chromatogr. A 2000, 885, 153.

19. Dias, A. N.; Simão, V.; Merib, J.; Carasek, E.; Anal. Chim. Acta 2013, 772, 33.

20. Budziak, D.; Martendal, E.; Carasek, E.; Anal. Chim. Acta 2008, $629,92$.

21. Hu, X.; Fan, Y.; Zhang, Y.; Dai, G.; Cai, Q.; Cao, Y.; Guo, C.; Anal. Chim. Acta 2012, 731, 40.
22. Yu, H.; Merib, J.; Anderson, J. L.; J. Chromatogr. A 2016, 1438, 10.

23. Bagheri, H.; Roostaie, A.; J. Chromatogr. A 2012, 1238, 22.

24. Carmo, S. N.; Merib, J.; Dias, A. N.; Stolberg, J.; Budziak, D.; Carasek, E.; J. Chromatogr. A 2017, 1525, 23.

25. Di Pietro Roux, K. C.; Jasinski, E. F.; Merib, J.; Sartorelli, M. L.; Carasek, E.; Anal. Methods 2016, 8, 5503.

26. Tan, L.; Crone, W. C.; Acta Mater. 2002, 50, 4449.

27. Auler, N. M. F.; Reis, M. S.; Guerra, M. P.; Nodari, R. O.; Genet. Mol. Biol. 2002, 25, 329.

28. Demirbas, A.; J. Hazard. Mater. 2008, 157, 220.

29. Statistica 8.0, Statsoft, USA, 2007.

30. European Parliament, Council of the European Union; Directive 2013/39/EU of the European Parliament and of the Council of 12 August 2013 amending Directives 2000/60/EC and 2008/105/EC as Regards Priority Substances in the Field of Water Policy; Official Journal of the European Union, 2013.

31. Menezes, H. C.; Paiva, M. J. N.; Santos, R. R.; Sousa, L. P.; Resende, S. F.; Saturnino, J. A.; Paulo, B. P.; Cardeal, Z. L.; Microchem. J. 2013, 110, 209.

32. Titato, G.; Lanças, F.; J. Liq. Chromatogr. Relat. Technol. 2005 , 28,3045 .
Submitted: April 16, 2018

Published online: June 22, 2018 